\title{
SPECIES COMPOSITION AND SEASONAL CAPTURE RATES OF TERRESTRIAL AMPHIPODS IN A LOWLAND AND HIGHLAND FOREST IN TASMANIA
}

\author{
by Andrew M. Walsh, Robert J. Taylor, Peter G. Cale and Raymond N. Brereton
}

(with four tables and five text-figures)

Wai.sh, A.M., Taylor, R.J., Cal.F, P.G. \& Brikrion R.N., 1994 (30:vi): Species composition and seasonal capture rates of terrestrial amphipods in a lowland and highland forest in Tasmania. Pap. Proc R. Soc. Tasm. 128: 57-62. https://doi.org/10.26749/rstpp.128.57 ISSN 0080-4703. Forest Practices Unit, Forestry Commission, 30 Patrick Street, Hobart, Tasmania, Australia 7000 (AMW, RJT, RNB); 260 Selby Street, Floreat Park Wcstern Australia, Australia 6014 (PGC).

Composition of the amphipod fauna and seasonal changes in captures in pitfall traps were compared at a lowland forest in northeastern Tasmania and three sites in highland forest in central Tasmania. The number of species at the highland sites (five) was greater than for the lowland area (two), possibly due to the greater development of the litter habitat and the moister, more humid conditions at the highland sites. Capture rates were correlated with temperature, but not rainfall, at both the lowland and highland areas. However, minium temperature was most significant for the highland sites, and maximum temperature was most significant at the lowland area. Captures at the highland sites were proportionally greater in autumn and lower in summer and showed a peak in October which was not present at the lowland area. Capture rates are most likely influenced by both activity levels and population size, as determined by seasonal reproductive patterns. It is, therefore, possible that the differences in the seasonality of captures at the highland and lowland areas may be related to different patterns of reproductive activity at the different altitudes.

Key Words: amphipods, capture rates, seasonality, climate, temperature, altitude, Tasmania.

\section{INTRODUCTION}

Tasmania contains a diverse assemblage of terrestrial amphipod crustaceans (family Talitridae) made up of at least 15 species (Friend 1987), most of which are found in the soil and litter. It is common to find up to five species in two or more genera in the same soil and litter sample. It has been hypothesised that competition for space rather than food regulates populations and that pairs of species differ in terms of vertical distribution, body size and breeding season (Friend \& Richardson 1977). Such niche partitioning is partly facilitated by differences in humidity and temperature tolerances, resulting in a number of species coexisting in the same site but in different levels of the soil and leaf litter. Richardson \& Devitt (1984) observed that on Mt Wellington Mysticotalitrus cryptus numbers declined sharply in the face of increasing numbers of Keratroides vulgaris in mid to lower altitude gullies, but at higher altitudes the two species coexisted, possibly due to the latter's competitive ability being reduced.

Terrestrial talitrids appear to be active at night and occur deeper in the soil and/or litter layer during the day (Friend $\&$ Richardson 1977, 1986). Activity can also be influenced by avoidance of detrimental environmental conditions, such as flooding (Friend \& Richardson 1986), and capture rates can be influenced by climatic factors such as temperature (McColl 1975).

In this study, the composition of the amphipod fauna and monthly capture rates are compared between two areas in Tasmania that differ in altitude, rainfall and temperature.

\section{METHODS}

\section{Study Areas}

Central Plateau

This study area consisted of three sites on the Central Plateau of Tasmania: D'Arcys Bluff (AMG 4420 53291, elevation $880 \mathrm{~m}, \mathrm{NW}$ aspect, $37 \mathrm{ha}$ ), Hornes Dam (AMG 4475 53196, $750 \mathrm{~m}, \mathrm{~S}$ aspect, $35 \mathrm{ha}$ ) and Butlers Road (AMG $447353164,700 \mathrm{~m}, \mathrm{~S}$ aspect, 20 ha) (fig. 1). Jurassic dolerite underlies all three sites and forms a variably dense surface cover of Quaternary talus. Snowfalls are common in winter and snow can lie for several weeks on the ground at the D'Arcys Bluff site.

Vegetation at all three sites was tall, open forest dominated by c. 150-200-year-old Eucalyptus delegatensis, closed forest dominated by Nothofagus cunninghamii, or intermediates between the two types. Only small areas of closed forest were present, at Hornes Dam and Butlers Road. Shrub and ground cover varied within sites, depending on canopy cover, dryness and surface rock abundance. The ground in wetter areas was bare under denser canopies, while the treefern Dicksonia antarctica was common in wetter, more open areas.

\section{Old Chum Dam}

This study area of 500 ha was located in northeastern Tasmania (fig.1), on the southeast-facing slopes to the north of Old Chum Dam (AMG 5880 54540) and in forest southwest of the dam. Altitude varied from 100-250 m and the geological substrate present was Ordovician granite.

The main eucalypt present was Eucalyptus obliqua. Eucalyptus amygdalina was subdominant over much of the area and dominant in some flatter drainage lines. Eucalyptus viminalis was widespread but uncommon. Understorey on most upper and middle slopes was very open, being dominated by bracken Pteridium esculentum. The undergrowth 


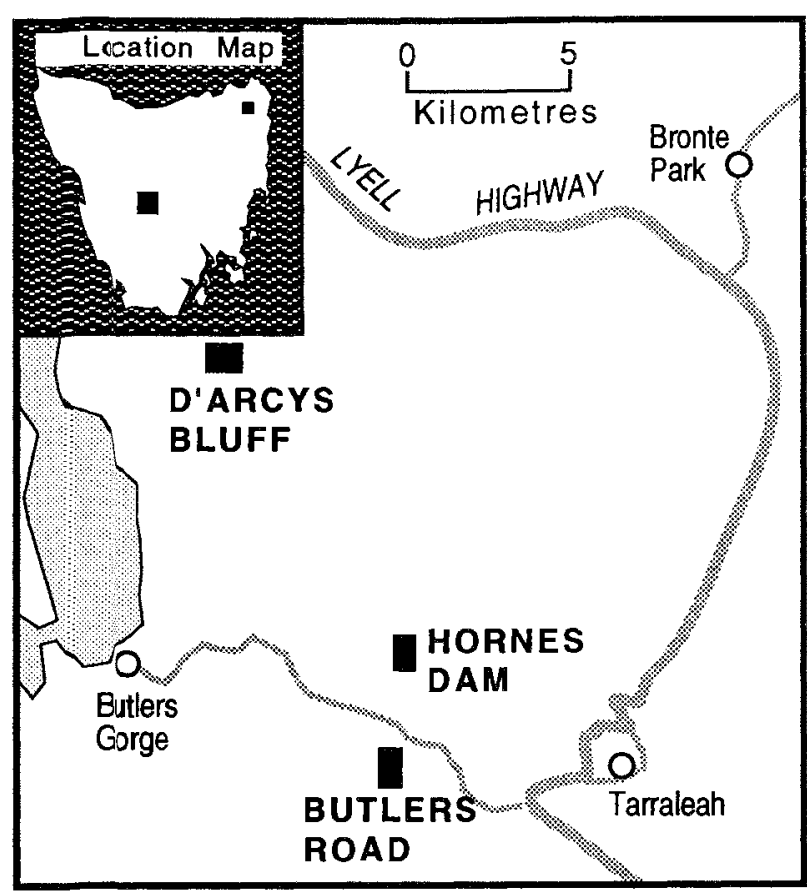

FIG. 1 - Location of the study areas. Inset: Old Chum Dam in the northeast and the Central Plateau sites in central Tasmania. Main map: the sites on the Central Plateau.

was shrubbier on slopes above creek lines and gullies with Acacia verticillata, Olearia lirata and $A$. terminalis being most common. On the south-facing mid to lower slopes, the soils were well drained and intermediate between wet and dry sclerophyll sites. Vegetation along creeklines was of two major types. Blackwood (Acacia melanoxylon) forest occurs along steep gullies and in some well-drained stream flats, with Dicksonia antarctica, Olearia argophylla, Pomaderris apetala, Coprosma quadrifida and Bursaria spinosa forming a dense, medium to tall shrub layer. The second type had an undergrowth dominated by dense, myrtaceous tea tree scrub, consisting of Melaleuca squarrosa and Leptospermum scoparium, and was associated with basins and soakages with impeded drainage and high soil moisture.

\section{Climatic Data}

For Old Chum Dam minimum and maximum daily temperatures and rainfall data were recorded on site during the census period. No climatic data were recorded for the sites on the Central Plateau. Instead, data for the town of Tarraleah near these sites (fig. 1) were obtained from the Bureau of Meteorology.

\section{Pitfall Trapping}

For the Central Plateau sites, 162 pitfall traps were used (30 at Butlers Road, 72 at Hornes Dam and 60 at D'Arcys Bluff) and at Old Chum Dam 180 pitfall traps. Each trap consisted of a plastic drinking cup ( $85 \mathrm{~mm}$ top diameter) placed into a buried section of PVC pipe so that the rim of the cup was flush with the ground surface and sheltered from rain by a plastic tray supported by small wooden sticks. At the Central Plateau sites, six traps were set out in a two-by-three-trap rectilinear grid at $10 \mathrm{~m}$ spacing between traps, with a total of 27 grids distributed over the three sites. At Old Chum Dam, a set of five of these pits was placed in two lines, one of three and another of two, with a spacing of $8-10 \mathrm{~m}$ between pits. At the start of a sampling interval, each trap was filled with c. $75 \mathrm{ml}$ of $50 \%$ ethanol $+5 \%$ glycerol as a preservative. During the summer months, pits in open areas were given a little more liquid to allow for evaporation. Traps were set and collected over a period of two to three days, depending on the time of year, and were left open for seven days each month. Sampling was undertaken at the Central Plateau sites between December 1991 and November 1992, and at Old Chum Dam between April 1989 and May 1990. Recovery of samples was reduced, duc to flooding of some traps from melting snow and removal of traps by native animals.

\section{Data Analysis}

Correlation analysis was used to examine similarities in the pattern of captures over months among species occurring in the same site and between the same species in different sites or areas. Only species and sites with sufficient numbers were analysed (the minimum used was 68 individuals captured over a 12 -month period). Multiple regression was used to investigate the influence of minimum and maximum temperatures, rainfall and raindays on capture rates. Climatic data collected during the periods when pitfall trapping was undertaken were used in the analysis. Rainfall in the seven days prior to each month's trapping period was also used at the Central Plateau sites. These data were not available for Old Chum Dam. Numbers of amphipods captured were logarithmically transformed before regression analysis. Analysis of covariance was used to compare the relationship between temperature and capture rates of Keratroides vulgaris at Old Chum Dam and Central Plateau.

\section{RESULTS}

Five species were found at Central Plateau sites and two species were collected at Old Chum Dam (table 1). Keratroides vulgaris was dominant at all sites and was the only species present at both Old Chum Dam and the Central Plateau. Although the species composition of the sites on the Central Plateau was the same (apart from the absence of Orchestiella neambulans at Butlers Road), relative abundance varied.

The pattern of captures over months (figs $2 \& 3$ ) was generally correlated for different species in the same site or area (table 2). Mysticotalitrus tasmaniae monthly captures were not correlated at Hornes Dam and D'Arcys Bluff (table 3). Keratroides vulgaris monthly captures were correlated at different sites on the Central Plateau, but these were not correlated with those obtained at Old Chum Dam (table 3). During October, most species at the Central Plateau sites showed a dramatic increase in captures that was not exhibited by amphipods at Old Chum Dam. Amphipods at the Central Plateau sites also showed proportionally greater capture rates in autumn and a less obvious peak in summer. 
TABLE 1

Capture rate and percentage of total captures for amphipods at Old Chum Dam and the Central Plateau

\begin{tabular}{|c|c|c|c|c|}
\hline \multirow[t]{2}{*}{ Specie: } & \multicolumn{3}{|c|}{ Cencral Plateau Sites } & Old Chum Dam \\
\hline & Butlers Road & Hornes Dam & D'Arcys Bluff & \\
\hline Keratrides vulgaris & $114^{*}(91.5) \dagger$ & $213 \quad(85.8)$ & $927(86.8)$ & $199 \quad(99.1)$ \\
\hline$K$ angulosus & - & - & - & $(0.9)$ \\
\hline Mysticotalitrus tasmaniate & $2.6 \quad(2.1)$ & $21 \quad(8.4)$ & $30.4 \quad(2.8)$ & - \\
\hline M. cryptus & $7.7 \quad(6.2)$ & $3.4 \quad(1.4)$ & $109(10.2)$ & - \\
\hline Neorchestia plicibrancha & $0.3 \quad(0.2)$ & $8.6 \quad(3.5)$ & $0.3(0.03)$ & - \\
\hline Orchestiella neambulans & $(0)$ & $2.2 \quad(0.9)$ & $1.4 \quad(0.1)$ & - \\
\hline Total captures & 439 & 1949 & 7487 & 4002 \\
\hline Number of pits/7 nights & 352 & 787 & 701 & 1993 \\
\hline
\end{tabular}

* Capure rates are expressed as numbers per 100 pits, calculated from pitfall trapping for seven days each month for a 12-month period.

$\dagger$ Percentage of total captures.

TABLE 2

Correlation coefficients for captures of different species* in the same sites

\begin{tabular}{lrr}
\hline Species comparison & $\mathrm{r}$ & \multicolumn{1}{c}{$\mathrm{p}$} \\
\hline Hornes Dam & & \\
K. vulgaris vs $M$. tasmaniae & 0.84 & $<0.001$ \\
K. vulgaris vs $N$. plicibrancha & 0.91 & $<0.001$ \\
M. tasmaniae vs $N$. plicibrancha & 0.73 & $<0.01$ \\
D'Arcys Bluff & & \\
K. vulgaris vs $M$. tasmaniae & 0.78 & $<0.01$ \\
K. vulgaris vs $M$. cryptus & 0.60 & $\mathrm{p}<0.05$ \\
M. tasmaniae vs M. cryptus & 0.31 & $\mathrm{~N} . S$. \\
Old Chum Dam & & \\
K. vulgaris vs $K$. angulosus & 0.81 & $\mathrm{p}<0.01$ \\
\hline
\end{tabular}

* Only those pairs of species with sufficient numbers for analysis were included.
TABLE 3

Correlation coefficients for captures of the same species in different sites and areas

\begin{tabular}{|c|c|c|c|c|}
\hline \multirow[t]{2}{*}{ Area comparison } & \multicolumn{2}{|c|}{$\begin{array}{c}\text { Keratroides } \\
\text { vulgaris }\end{array}$} & \multicolumn{2}{|c|}{$\begin{array}{c}\text { Mysticotalitrus } \\
\text { tasmaniae }\end{array}$} \\
\hline & $r$ & $\mathrm{p}$ & г & $\mathrm{p}$ \\
\hline $\begin{array}{l}\text { Butlers Road } \\
\text { vs Hornes Dam }\end{array}$ & 0.88 & $<0.001$ & - & - \\
\hline $\begin{array}{l}\text { Butlers Road } \\
\text { vs D'Arcys Bluff }\end{array}$ & 0.75 & $<0.01$ & & - \\
\hline $\begin{array}{l}\text { Hornes Dam } \\
\text { vs D'Arcys Bluff }\end{array}$ & 0.69 & $<0.05$ & 0.36 & N.S. \\
\hline $\begin{array}{l}\text { Central Plateau } \\
\text { vs Old Chum Dam }\end{array}$ & 0.45 & N.S. & - & - \\
\hline
\end{tabular}

TABLE 4

Correlations between captures of amphipods and mean temperatures

\begin{tabular}{|c|c|c|c|c|}
\hline \multirow[t]{2}{*}{ Species/sites } & \multicolumn{2}{|c|}{ Min. temperature } & \multicolumn{2}{|c|}{ Max. temperature } \\
\hline & $\mathrm{r}$ & $\mathrm{p}$ & $\Gamma$ & $\mathrm{p}$ \\
\hline \multicolumn{5}{|l|}{ Keratroudes vulgaris } \\
\hline \multicolumn{5}{|l|}{ Central Plateau } \\
\hline D'Arcys Bluff & 0.59 & $<0.05$ & 0.54 & N.S. \\
\hline Hornes Dam & 0.83 & $<0.001$ & 0.66 & $<0.05$ \\
\hline Butlers Road & 0.86 & $<0.001$ & 0.70 & $<0.005$ \\
\hline Old Chum Dam & 0.87 & $<0.001$ & 0.95 & $<0.001$ \\
\hline \multicolumn{5}{|c|}{ Mysticotalitrus tasmaniae } \\
\hline Hornes Dam & 0.67 & $<0.05$ & 0.62 & $<0.05$ \\
\hline \multicolumn{5}{|l|}{ Neorchestia plicibrancha } \\
\hline Hornes Dam & 0.61 & $<0.05$ & 0.52 & N. S. \\
\hline
\end{tabular}



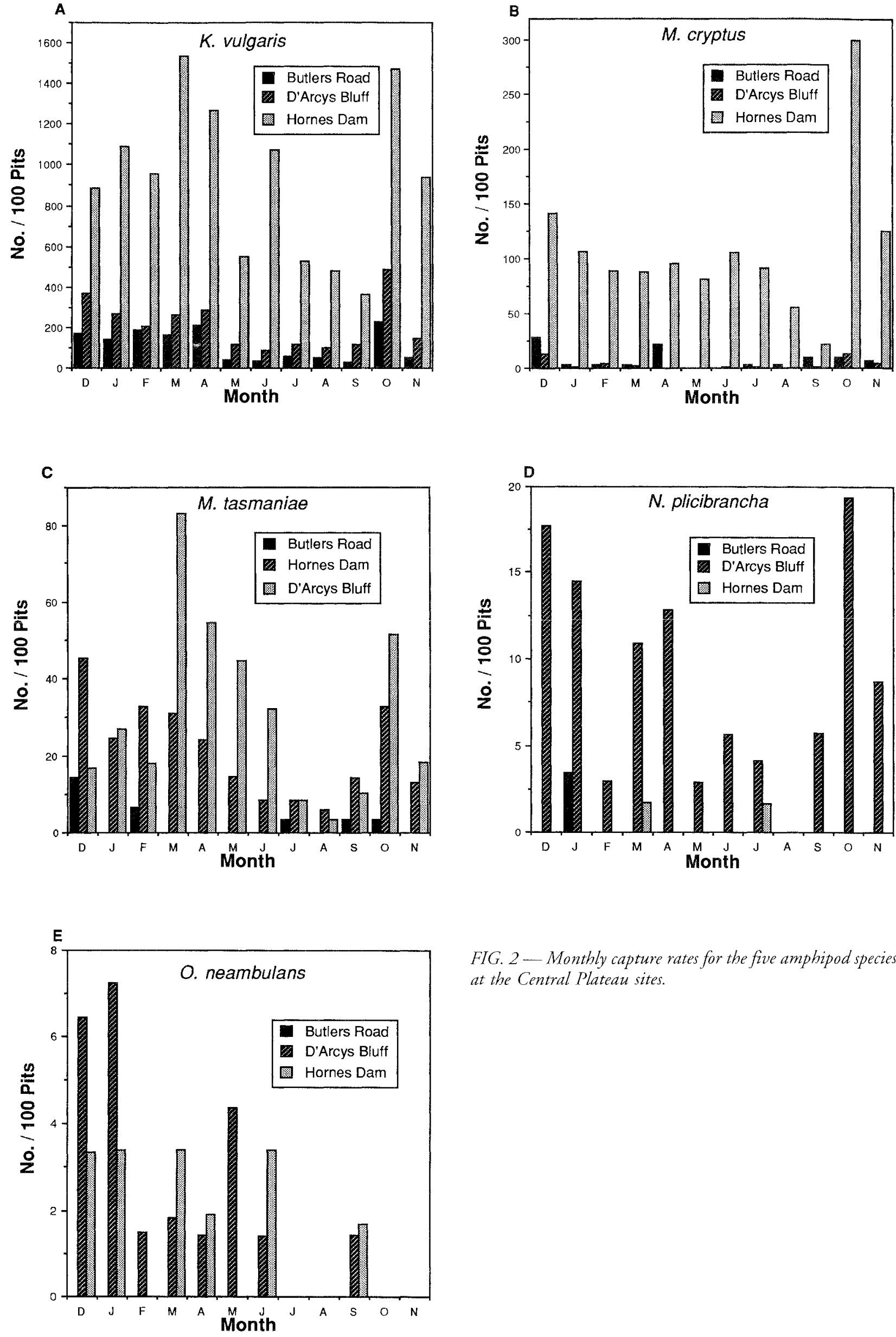

FIG. 2 - Monthly capture rates for the five amphipod species at the Central Plateau sites. 
At the Central Plateau sites minimum temperatures were lower and rainfall was higher than at Old Chum Dam (figs $4 \&$ 5). Only a few species were captured frequently enough to allow a multiple regression analysis of the influence of climatic variables on capture rates. At the Central Plateau sites, minimum temperature was consistently most highly correlated with capture rate, while at Old Chum Dam maximum temperature was most strongly correlated with capture rates (table 4). Temperature was more highly correlated with capture rates at Old Chum Dam than at the Central Plateau sites. Addition of rainfall variables (total rainfall an d number of raindays, both during and for seven days prior to trapping) did not add significantly to the explanation of variation in capture rates. The rate of change in captures with changes in minimum temperature did not differ significantly (analysis of covariance, $F_{(1,20)}=1.3$ ) between populations of $K$. vulgaris at the Central Plateau and at Old Chum Dam.

\section{DISCUSSION}

The capture rate of amphipods in the pitfall traps is probably a reflection of both activity levels and population size. Studies have shown that population size of terrestrial amhpipods, measured by sampling individuals directly from the litter and soil, changed during the year (Duncan 1969, Tamura \& Koseki 1974), and that these changes were due to seasonal reproductive patterns. In New Zealand forests, McColl (1975) found that changes in temperature over the period of a year correlated with capture rates of amphipods. However, in their study of an amphipod community in southwestern Tasmania dominated by Austrotroides maritimus, Richardson et al. (1991) found no change in capture rate over a ten-day period in summer, despite the passage of a cold front that brought a noticeable change in the weather. The differences between these two studies suggest that capture rares may be more influenced by population density than by activity levels. The chance of capture probably increases with body size within a species,

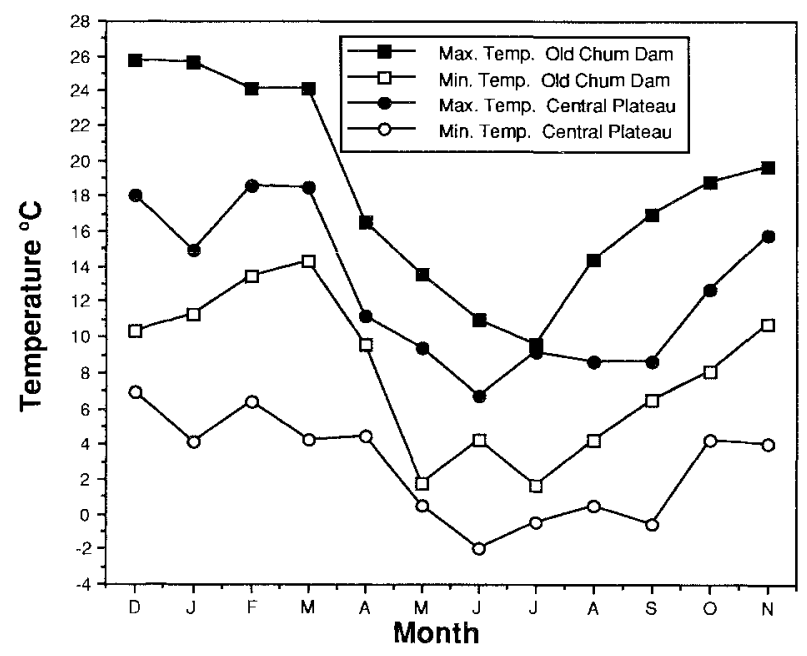

FIG. 4 - Mean temperatures for the study areas during the census periods.

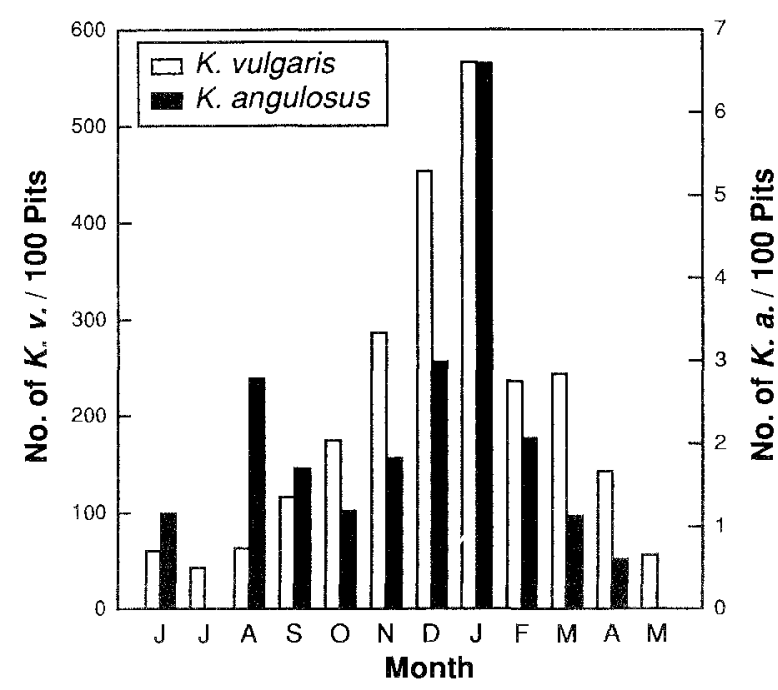

FIG. 3 - Monthly capture rates for amphipod species at Old Chum Dam.

and, hence, the age structure of the populations may also have influenced the results.

Since the traps were open for about a quarter of the year, it is possible that trapping could have led to depletion of populations around trap sites. However, there is no such trend apparent in the data, apart from the relatively immobile Orchestiella neambulans (fig. 2E).

The capture rates of amphipods were found to be most influenced by temperature. In the colder sites at the Central Plateau, where temperatures during the year tange between $-2^{\circ}$ and $19^{\circ} \mathrm{C}$, amphipod captures were more closely correlated with minimum rather than maximum temperature, whereas the reverse was the case at the warmer area at Old Chum Dam. The more open vegetation at Old Chum Dam probably allows penetration of sunlight to the ground surface to a greater extent than at the Central Plateau sites, where a dense secondary tree layer or shrub layer often shades the ground. Litter temperatures at night

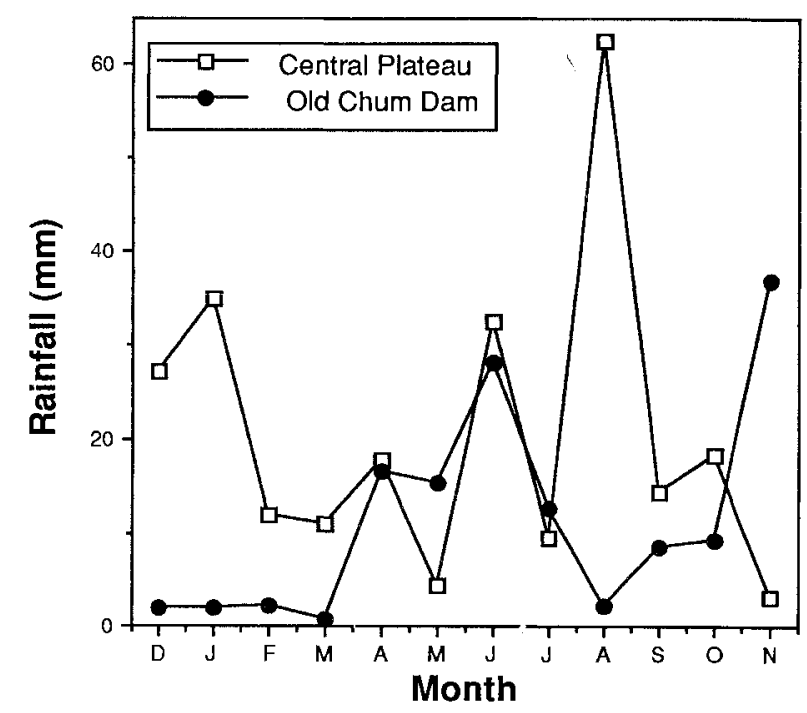

FIG. 5 - Rainfall (mm/7 days/month) at the study areas during the census periods. 
at Old Chum Dam, thus, may follow maximum temperature mo re closely, particularly as frosts are rare. At a site in eastern Tasmania with a mild climate similar to that at OId Chum Dam, Friend \& Richardson (1977) showed that on a cold day in autumn soil and litter temperatures at night stayed warmer than air temperatures, but on a warm day ove rnight soil and litter temperatures were similar to air temperatures. McColl (1975) also found minimum temperature to be correlated with monthly captures of amphipods in a wet Nothofagus forest in New Zealand.

Neorchestia plicibrancha, Mysticotalitrus cryptus and, to a lesserextent, $M$. tasmaniae and Keratroides vulgaris all showed a la rge increase in capture rates in October at the Central Plateau sites. Such an increase was much larger than expected on the basis of temperatures for that month. However, therewas a large increase in temperatures between September and October, and this flush of captures coincided with a return to warmer spring conditions. Perhaps favourable moisture conditions which remained from the heavy rain in August (fig. 5) acted in concert with the increasing temperatures to produce the peak in activity. Alternatively, the higher capture rates could be related to reproductive activity, with a greater mobility of males and/or a flush of juveniles at this time. If this is correct, it implies a difference in the timing of breeding between the Central Plateau and the Old Chum Dam populations. Mysticotalitrus tasmaniae and $K$. vulgaris at $\mathrm{D}^{\prime}$ Arcys Bluff also exhibited relatively high captures in March and April, before the fall in minimum temperatures to the colder autumn/winter period (fig. 4). Such a pattern is not totally explained by temperature, as temperatures were higher in February but capture rates were substantially lower.

The composition of the amphipod fauna at Old Chum Dam is the same as that found by Friend \& Richardson (1977) at a site in eastern Tasmania, where K. vulgaris and $K$ angulosus differed in their vertical distribution, with $K$ angulosus occurring deeper in the soil/litter profile (at least for part of the time) and $K$. vulgaris engaging in longer periods of intense activity in laboratory trials. Both these characteristics make $K$. vulgaris more susceptible to capture in pitfall traps. Therefore, the differences in abundance of $K$. vulgaris and $K$. angulosus at Old Chum Dam are likely to be less than indicated by capture rates.

At the Central Plateau sites more species were captured, despite a smaller area being trapped with fewer pitfalls, and abundance at two of these sites was also greater than at Old Chum Dam. This difference may be related to biogeographic factors, in that more species are present in western than in eastern Tasmania. However, ecological factors may also be involved. There is a greater development of the litter habitat at the Central Plateau sites, due to the higher biomass of vegetation and the lower frequency of fires. The lower temperatures may also reduce the decomposition rates of litter. Additionally, higher rainfall and the greater shading of the litter at the Central Plateau sites may favour amphipods, due to their preference for moist, humid environments. The greater development of litter at the Central Plateau may allow greater partitioning of habitat space, which is probably a limiting resource (Friend \& Richardson 1986). Species may also subdivide habitat on the basis of their water regimes, with some species preferring moist gully bottoms (Richardson \& Devitt 1984, Friend \& Richardson 1986). The three most abundant species at the Central Plateau site were the same species found by Richardson \& Devitt (1984) in wet forest below $1000 \mathrm{~m}$ on
Mt Wellington in southeastern Tasmania. Richardson \& Devitt (1984) found differences in the relative abundance of the species at different locations across a gully and vertical separation of $K$. vulgaris and $M$. tasmaniae, with $M$. tasmaniae being more active in the upper layers and on the litter surface.

Neorchestia plicibrancha was also recorded by Richardson \& Devitt (1984) on Mt Wellington, but it was very restricted, occurring between 1000 and $1200 \mathrm{~m}$ in the coolest, most shaded sites. Neorchestia plicibrancha was also uncommon on our study sites. However, this species is very common in rainforest in the west (A. Richardson, pers. comm.). The other rarely captured species, $O$. neambulans, was found on only two of the Central Plateau sites and represented $0.3 \%$ of the catch at these sites.

This study found that temperature was most influential in determining capture rates of amphipods at the surface of the litter. It was expected that moisture would also influence capture rates. However, no evidence for this was found, possibly due to our lack of a litter moisture index as opposed to simple rainfall statistics. Moisture is certainly influential in determining distribution of species within a site and the cooler, wetter sites with a higher vegetation cover on the Central Plateau were more species rich and usually supported a higher abundance of amphipods than the warmer, drier area in northeasternTasmania.

\section{ACKNOWLEDGEMENTS}

Staff from the Fingal and Tarraleah offices of the Forestry Commission provided logistical support. Dr Alastair Richardson confirmed our species identifications and provided comments on a previous draft. Funding was provided by the Forest Ecology Research Fund.

\section{REFERENCES}

DUNCAN, K.W., 1969: The ecology of two species of terrestrial Amphipoda (Crustacea: Family Talitridae) living in waste grassland. Pedobiology 9: 323-341.

Friend, J.A., 1987: The Terrestrial Amphipods (Amphipoda: Talitridae) of Tasmania: Systematics and zoogeography. Rec. Aust. Mus. Suppl. 7: 1-85.

Frit.ND, J.A. \& Richardson, A.M.M., 1977: A preliminary study of niche partition in two Tasmanian terrestrial amphipod species. In Lohm, U. \& Persson, T. (Eds): Soil organisms as components of ecosystems. Ecol. Bull. (Stockholm) 25: 24-35.

Friend, J.A. \& Richardson, A.M.M., 1986: Biology of terrestrial amphipods. Ann. Rev. Entomol. 31: 25-48.

McCol., P.H., 1975: The invertebrate fauna of the litter surface of a Nothofagus truncata forest floor, and the effect of microclimate on activity. $N Z$ J. Zool. 2: 15-34

Richardson, A.M.M. \& DivitT, D.M., 1984: The distribution of four species of terrestrial amphipods (Crustacea, Amphipoda: Talitridae) on Mt. Wellington, Tasmania. Aust. Zool. 21:143-156.

Richarijson, A.M.M., Swain, R. \& Smith, S.J., 1991: Local distributions of sandhoppers and landhoppers (Crustacea: Amphipoda: Talitridae) in the coastal zone of western Tasmania. Hydrobiology 223: 127-140.

Tamura, H. \& KoSf.KI, K., 1974: Population study on a terrestrial amphipod, Orchestia platensis japonica (Tattersall), in a temperate forest. Jap. J. Ecol. 24: 123-139. 